\title{
A LIBRAS E SUA CAPACIDADE DE ROMPER O SILÊNCIO ENTRE FAMÍLIA OUVINTE E FILHO SURDO*
}

\author{
Valéria da Silva Bezerra \\ Sueli Salles Fidalgo
}

\section{Introdução}

Estudos nas áreas de Educação e Linguística Aplicada, entre outras, ressaltam a importância do processo de ensino-aprendizagem da linguagem para o desenvolvimento cognitivo, social e cultural de qualquer criança. A perspectiva histórico-cultural vygotskiana é uma das maiores referências sobre a relação social de linguagem-desenvolvimento humano. Sobre a relação entre a manipulação de objetos e a atividade simbólica, Vygotsky ([1934] 1991) foi o teórico que, diferente de seus contemporâneos, percebeu que, no momento em que esses dois aspectos se conectam na vida prática humana, surge o início da inteligência prática e abstrata. Vygotsky ([1931] 1997a) discorreu ainda em sua teoria sobre os vínculos intrínsecos entre o desenvolvimento das funções psicológicas superiores humanas (o pensamento em conceito, a memória, a atenção voluntária, percepção, a linguagem interior) e as relações sociais humanas.

O teórico estudou o fundamento do desenvolvimento humano não pelo viés biológico, mas pela realidade cultural da criança e expõe que o desenvolvimento do homem é processo e produto social no qual a aprendizagem é o fator que o antecede e o provoca. Desta forma, Vygotsky ([1931] 1997a, [1934] 2001) define o desenvolvimento não como advindo de um acúmulo gradual de mudanças isoladas, mas como um complexo processo dialético que implica tempos variados para funções distintas e mudanças qualitativas. A produção de instrumentos técnicos e semióticos é o fundamento maior desse processo.

Diferente dos outros animais, o homem se constrói e se transforma nesse decurso. Em outras palavras, no decorrer de sua atividade prática e produtiva, o ser humano cria instrumentos, como os signos. Esses

*DOI - 10.29388/978-65-86678-60-4-0-f.355-382 
instrumentos são construções históricas e funcionam, concomitantemente, como meio de interação e modo de operação mental (SMOLKA; LAPLANE, 2005). Desse modo, o signo possibilita que a experiência humana seja um construto de significações, partilhas, reflexões no nível social e individual.

Para a teoria histórico-cultural, o signo funciona como um elemento mediador, operador e transformador das relações coletivas e funções mentais. Nessa perspectiva, a palavra, o signo, emerge das inter-relações sociais e opera mudanças na própria atividade humana (VYGOTSKY, [1934] 1991). Assim, a significação, de natureza social, é concebida como a produção material de signos e sentidos.

O ensino-aprendizagem da língua e o desenvolvimento de tudo o que ele desencadeia, de acordo com a perspectiva vygotskiana, resulta do processo de socialização que experienciamos desde o nascimento. A família é, geralmente, a primeira instituição social em que vivenciamos o processo de interação e socialização; daí o seu papel fundamental para o desenvolvimento da língua. É nos momentos de interação com os pais, ou outros adultos que exercem esse papel, que surgem a estimulação, a apropriação e o desenvolvimento da língua.

Todavia, esse processo se estrutura de modo distinto com crianças surdas de pais ouvintes. A ausência da audição bloqueia a apreensão da língua oral utilizada pela família. Sabe-se que a maioria das crianças surdas, por volta de 95\%, é filha de pais ouvintes (Cf. YUE, 2010). Esse aspecto resulta na ausência de uma língua comum para a comunicação, pois a criança não poderá usar o canal auditivo e, com isso, não há possibilidade de aprendizagem da língua oral de forma natural ${ }^{1}$. A língua que poderia ser apreendida desde a mais tenra idade (a língua de sinais) ${ }^{2}$ é, na maioria dos casos, desconhecida

\footnotetext{
${ }^{1}$ A língua oral pode ser aprendida pelo surdo com o auxílio de sessões com fonoaudiólogos e outros tratamentos, mas esse não é o caminho utilizado pela maior parte das crianças, que aprende sua primeira língua naturalmente, em interações com pares e adultos. Por isso, o uso do termo "língua natural" nesse caso.

${ }^{2}$ Vygotsky ([1930] 1997b; [s/d] 1997c) diz que a falta de acesso à língua oral não impede a criança surda de desenvolver a linguagem e suas funções superiores da atividade intelectual. É por meio de uma língua espaço-visual que despontarão as manifestações e desenvolvimentos interacionais, sociais e intelectuais. Assim, as regularidades que comandam o desenvolvimento do pensamento verbal da criança surda são as mesmas que as da criança ouvinte. O que difere é somente sua manifestação por intermédio de uma língua específica (no caso das crianças surdas brasileiras, a LIBRAS). Em outras palavras, não é a ausência de língua oral que impedirá o desenvolvimento das Funções Psicológicas Superiores. É a ausência de uma língua.
} 
pelos pais ouvintes. É no contexto familiar, geralmente, que se inicia a interação social, possibilitando o desenvolvimento da língua. Todavia, a dificuldade na comunicação faz com que as interações entre pais ouvintes e filhos surdos se restrinjam, resultando, muitas vezes, em atraso no desenvolvimento linguístico dessas crianças.

Como já sublinhado, a vertente histórico-cultural afirma que a língua é um fator fundamental para o desenvolvimento do pensamento verbal da criança e, consequentemente, da sua cognição. Segundo Monteiro (2013), esse processo acontece em seus ambientes sociais (como o familiar e o escolar, por exemplo) em interação com seus pais, professores e amigos. No caso das crianças ouvintes, a língua vem como herança de seus pais e familiares. $\mathrm{Na}$ escola, ela é aperfeiçoada. Ademais, é nesse ambiente que o indivíduo estará exposto aos fatores e valores linguísticos, históricos, sociais e culturais que a sua primeira língua carrega.

Infelizmente, as crianças surdas de pais ouvintes não recebem essa herança linguística. Além disso, fatores como a demora na descoberta da surdez, falta de orientação e suportes fazem com que esses familiares não saibam da importância da língua de sinais para o desenvolvimento dos seus filhos e para o bom andamento das relações familiares. A ausência de uma língua partilhada no seio familiar traz diversas consequências. Entre elas, o que Finau (2006, p. 219) discute, quando diz que o atraso no contato com a língua de sinais desde a mais tenra idade resulta em implicações negativas para o desenvolvimento cognitivo da criança surda, uma vez que seria por meio da língua que a criança sofisticaria habilidades como abstração, memorização (que são críticas para o seu desenvolvimento pessoal), bem como para processar e reelaborar as informações do mundo, que the facilitariam a compreensão linguística real de sua $\mathrm{L1}^{3}$ e auxiliariam no processo de ensinoaprendizagem de sua $\mathrm{L} 2$.

Além das implicações linguísticas, o atraso no processo de ensinoaprendizado da língua de sinais e o seu não uso no contexto familiar interferem também na construção de laços afetivos do filho surdo com os pais ouvintes e, de certo modo, na estruturação de sua identidade. Sobre essa relação, Góes (2012, p. 42-43) expõe que:

\footnotetext{
${ }^{3}$ L1 é abreviação para língua primeira e L2 para língua segunda.
} 
[...] a oportunidade de incorporação de uma língua de sinais mostra-se necessária para que sejam configuradas condições mais propícias à expansão das relações interpessoais, que constituem o funcionamento nas esferas cognitiva e afetiva e fundam a construção da subjetividade. Portanto, os problemas tradicionalmente apontados como característicos da pessoa surda são produzidos por condições sociais. Não há limitações cognitivas ou afetivas inerentes à surdez, tudo dependendo das possibilidades oferecidas pelo grupo social para seu desenvolvimento, em especial para a consolidação da linguagem.

Assim, a interação familiar por meio da Libras ocupa um papel fundamental não só no desenvolvimento linguístico, social e cognitivo do surdo, mas também nas ligações interpessoais do mesmo com a família ouvinte, e como resultado, na sua relação com o português e a comunidade majoritária (FINAU, 2006).

Isso revela que o ensino da Libras para pais ouvintes pode interferir de modo extremamente positivo e transformador em diversos aspectos. Pensando nessas questões, o presente trabalho expõe os resultados de uma pesquisa que demonstrou como a Libras mudou, de modo significativo, a comunicação entre pais ouvintes e filho surdo. Para tanto, foi acompanhado o processo de ensino-aprendizagem de pais ouvintes de uma criança surda que frequentavam o curso de Libras como L2 ofertado por uma EMEBS ${ }^{4}$ para toda a comunidade escolar. $O$ intuito foi caminhar junto com esses pais a fim de compreender como a inserção nessa língua poderia transformar o processo de interação e comunicação - e o que deles resulta ${ }^{5}$.

Desse modo, num primeiro momento, serão apresentadas as bases teóricas do trabalho. Em seguida, será exposta a perspectiva teóricometodológica, incluindo os procedimentos de produção e análise de dados. Posteriormente, traremos a discussão dos dados e, por fim, as considerações finais.

\footnotetext{
${ }^{4}$ Escola Municipal de Educação Bilíngue para Surdos (município de São Paulo).

${ }^{5} \mathrm{O}$ presente trabalho é uma parte dos resultados obtidos pela pesquisa de Bezerra (2019) desenvolvida sob a orientação da professora doutora Sueli Salles Fidalgo.
} 


\section{Bases teóricas}

Esta pesquisa propõe as sessões reflexivas ${ }^{6}$ como instrumento de um processo de construção e ressignificação (AGUIAR, SOARES e MACHADO, 2015) ou transformação de conceitos e práticas dos participantes (MAGALHÃES, [1998] 2007b). Estes são membros da família de um aluno surdo e, assim como a criança, são alunos de uma EMEBS, mas enquanto a criança está matriculada na Educação Infantil da escola, os pais fazem o curso de Libras oferecido pela instituição. As pesquisadoras também se encaixam como participantes, visto que para a metodologia de pesquisa adotada, todos estão em uma relação dialética em que, por meio das contradições, dos conflitos (que são postos pelas perguntas feitas nos diálogos) e pela negociação de significados que resulta desse processo nas sessões reflexivas, todos ressignificam seus conceitos ou transformam suas práticas. No entanto, neste trabalho, as falas das pesquisadoras não serão alvo de análise.

Esse propósito de construção de reflexão crítica à transformação segue a concepção de que essas famílias se constituem sob a influência de outros agentes e instituições culturalmente estabelecidos como fonte de verdades que são assumidas por eles como resultado de suas vivências de mundo. Magalhães ([1994] 2007a, p. 62), com base em Gouldner (1982), expõe que

[...] as escolhas que fazemos e o significado que atribuímos às situações são embasados em hipóteses que construímos através de nossas experiências (background assumptions). Essas hipóteses vão das mais gerais - hipóteses de mundo - que embasam as orientações mais amplas que dão significado ao não familiar, às mais particulares, aplicadas apenas a membros de um determinado domínio.

Desse modo, a forma como essas famílias definem a surdez de seus filhos, a maneira como encaram o processo de ensino-aprendizagem no curso, os valores e sentidos que dão à língua de sinais são estruturados por hipóteses que adquiriram em suas vivências. Em muitos casos, a notícia da surdez é dada a essas famílias por médicos que, em sua maioria, a encaram pela perspectiva da falta de audição (defeito, perda de um sentido). Nesse instante, essas famílias recebem a confirmação da concepção do senso comum que é

\footnotetext{
${ }^{6}$ Sobre o que é sessão reflexiva, no tópico Metodologia.
} 
impregnada pela visão da surdez como falta, como defeito (VYGOTSKY, [1931] 1997a).

Respaldadas pelo legislativo do país (Lei 10.436/02 e Decreto 5626/05) e com base nos estudos educacionais, sociológicos, antropológicos e linguísticos sobre a surdez (FINAU, 2006; LACERDA; LODI, 2009; GESSER, 2009; GOES, 2012; LACERDA, 2013; SOUZA, 2017) as Escolas Municipais de Educação Bilíngue para Surdos (EMEBS) são exemplos de instituições educacionais que possibilitam para os familiares ouvintes o contato com outra visão sobre a surdez e a Libras.

Ao entrarem com seus filhos no contexto escolar de perspectiva bilíngue, uma nova concepção de surdez lhes é apresentada. Dificilmente pais ouvintes sabem a Libras antes de conhecer uma instituição educacional bilíngue (SOUZA, 2017). Isso ocorre porque durante um longo período histórico as línguas de sinais não foram reconhecidas como língua, mas vistas como mímica, gesto ou linguagem rudimentar (SKLIAR, 1998; PERLIN, 1998; SANTANA, 2004; FERNANDES, 2007, 2012; GESSER, 2009). Essa visão historicamente enraizada na sociedade reflete nas concepções que os pais ouvintes têm sobre a Libras. A escola bilíngue apresenta aos pais outra concepção sobre seu filho: não mais uma criança com defeito, mas componente de uma minoria linguística, usuário de uma língua até então por eles desconhecida e de modalidade totalmente distinta da sua.

Ressignificar a visão de limitação, perda e falta dos filhos pela de potencialidades e possibilidades de desenvolvimento cognitivo, social, linguístico (educacional em geral) emerge como uma ruptura brusca de sentido reconstruído a partir de um significado coletivo diferente do que tinham até então (perspectiva do senso comum e, de certo modo, reafirmada pela área médico-terapêutica).

No entanto, mesmo quando os familiares aceitam o contexto escolar de perspectiva bilíngue para seus filhos, isso não é, em muitos casos, sinônimo de que sua perspectiva de surdez como defeito foi abandonada. Muitas vezes, eles apenas aceitam a "ajuda" que em outras instituições não receberam. Outras vezes, têm uma visão de que quanto mais eles puderem fazer e quanto mais oportunidades derem às crianças, melhor. 
Não defendemos que haja qualquer problema com o se querer oferecer o maior número de oportunidades aos filhos - surdos ou ouvintes. No entanto, se a visão dos pais ainda estiver carregada pelo senso comum de que à criança surda Ihe falta alguma coisa (i.e., a audição), muitas vezes, eles passarão anos buscando cirurgias e implantes, sem que isso represente qualquer possibilidade de maior desenvolvimento para os filhos, a menos que haja dinheiro e/ou oportunidade para tratamento fonoaudiológico. Por puro desconhecimento sobre o que significa essa visão do defeito e como se daria todo o "tratamento de recuperação", os pais, muitas vezes, tentam aliar à perspectiva educacional, que enfatiza a necessidade do ensino-aprendizado de outra língua (Libras), com o trabalho penoso e desgastante do "tratamento" - o que indica que ainda acreditam que a surdez é uma doença.

Vale destacar que os profissionais que seguem a visão fonoaudiológica e os da educação podem trabalhar juntos para a formação da criança surda, ou seja, não há necessidade de as ações serem dicotomizadas (SANTANA, 2004; SANTANA; GUARINELLO; BERGAMO, 2013). Todavia, é fundamental que, em ambos os processos, a criança surda seja respeitada como participante de uma minoria linguística e o andamento dos trabalhos nas duas áreas tenha como língua mediadora principal a Libras.

A compreensão crítica, questionamentos e transformação das crenças e valores que dão forma às ações desses pais na interação com os filhos, assim como a concepção que têm sobre a surdez e a Libras, não é algo que ocorre de forma simples, nem é natural ou adquirida. É, como tudo que se aprende, um processo sócio-histórico-cultural que inclui perguntas, muitas vezes vivenciadas de forma sofrida: Como encarar a surdez não mais como deficiência, mas como diferença linguística e cultural? A Libras é a língua do meu filho ou apenas uma "ajuda" na interação? Será que a Libras é importante para a relação e interação com o meu filho ou seria melhor que ele "se curasse" e ouvisse?

De acordo com Kemmis (1987, p. 76), refletir de forma crítica

[...] é localizar-se em um quadro de ação, localizar-se na história de uma situação, participar de uma atividade social e tomar partido em questões. Porque a reflexão crítica bem-sucedida tem consequências públicas (transformações), é sempre uma atividade pública, pressagiando uma forma de crítica organizada e sistemática em que as 
pessoas colaboram para o desenvolvimento de suas próprias teorias e práticas sociais e as condições de seu próprio trabalho (tradução nossa) ${ }^{7}$.

Nesse sentido, os pais ouvintes e pesquisadoras, ao refletirem criticamente sobre suas ações, possibilitam, de acordo com o definido por Liberali (2008, p. 42), uma emancipação, já que a confrontação com a realidade e valores éticos traz "a chance de transformação informada pela ação". Assim, os participantes dessa pesquisa carregam significações que podem ser percebidas em suas falas e ações. Ao resgatá-las, por meio das sessões reflexivas, temos como proposta examiná-las, buscando ressignificações e transformações.

\section{Metodologia}

Sobre a metodologia, este trabalho segue a pesquisa crítica de colaboração (PCCol) que, no Brasil, tem sido pensada principalmente por Magalhães e colaboradores(as) (FIDALGO; MAGALHÃES, 2021; LIBERALI, 2019; MAGALHÃES, 2004, 2011, [1994] 2007a; ARANHA, 2009; NININ e MAGALHÃES, 2017; MAGALHÃES e FIDALGO, 2019). Trata-se de uma metodologia que, como o nome indica, se insere no paradigma crítico de pesquisa. Assim se define por buscar a transformação de situações sociais de iniquidade, promovendo espaços de emancipação e ressignificação da lingua(gem), ou seja, da língua em ação. Quem utiliza essa metodologia entende, como os membros do grupo $\operatorname{ILCAE}^{8}$ de pesquisa - um dos grupos nos quais este trabalho se insere -, que a linguagem pode ser usada para manter o status quo, o estado da arte de exclusão social-educacional em que muitos se encontram, ou pode, em

\footnotetext{
${ }^{7}$ Texto original: to reflect critically is to locate oneself in an action frame, to locate oneself in the history of a situation, participate in a social activity, and to take sides on issues. Because successful critical reflection has public consequences (transformations of these kinds), it is always a public activity, presaging an organized, systematic form of critique in which people collaborate in the development of their own social theory and practice, and the conditions of their own work (tradução nossa).

${ }^{8}$ As pesquisadoras atuam em 3 grupos de pesquisa, a saber: ILCAE - Inclusão Linguística em Cenários de Atividades Educacionais; ISEF - Inclusão Social-Educacional e Formação - e GEICS Grupo de Pesquisa: Estudos sobre Identidade e Cultura Surdas. Os dois primeiros estão cadastrados no CNPq e certificados pela PUC-SP (o ILCAE) e pela UNIFESP (o ISEF). O terceiro encontra-se em fase de recadastramento.
} 
contrapartida, ser usada para questionar as situações excludentes encontradas. Seguimos a última.

Para que haja alguma condição de emancipação, é fundamental iniciar o processo pela mudança do termo com o qual chamamos aqueles que estão na pesquisa: não são objetos de pesquisa e nem sujeitos. São, para nós, participantes como os pesquisadores e, como eles, as suas colocações, perguntas e contradições criam espaços de zona de desenvolvimento proximal (VYGOTSKY, [1934] 1991) para os demais (incluindo as pesquisadoras), fazendo com que cada um repense a sua visão, as suas certezas e as suas ações, dialeticamente, dialogicamente e colaborativamente. Ao considerar os envolvidos na pesquisa como participantes, na PCCol, nós os definimos como agentes ativos no processo sócio-histórico e cultural, o que significa, segundo Bourdieu (1982, apud MAGALHÃES, [1994] 2007a, p. 60), criar espaços para que todos desenvolvam a capacidade de refletir sobre suas "próprias ações simbólicas ou instrumentais, entend[am] as contradições do processo social e transform[em]-se como resultado de um processo de conscientização sobre o relacionamento, propósito e ação". Com isso, seguindo a PCCol, neste trabalho, demonstramos como os participantes (familiares e pesquisadoras) caminham ao encontro de consciências na construção de seus discursos e de suas ações a partir de diálogos - imprescindíveis para a transformação social.

Esta pesquisa ocorreu em uma EMEBS, instituições que atende, desde a Educação Infantil até o 9o ano do Ensino Fundamental. Nas turmas das diversas séries, é estabelecida como primeira língua a Libras, sendo usada para a ministração de todas as disciplinas. A língua portuguesa é segunda língua, ensinada na modalidade escrita. Como apontado acima, a escola também oferta curso livre de Libras, gratuito, como segunda língua aberto para toda a comunidade escolar.

Durante a pesquisa de cujos dados resultou este artigo, foi acompanhado o processo de ensino-aprendizagem de Libras dos pais ouvintes (Nina, a mãe e Pedro, o padrasto) de Gustavo ${ }^{9}$, um aluno surdo de uma turma da Educação Infantil da EMEBS. Caminhamos junto com esses pais em busca de responder a seguinte pergunta de pesquisa: como a inserção nessa língua transformou o processo de interação e comunicação neste contexto familiar?

\footnotetext{
${ }^{9}$ Nomes dos pais participantes e do filho surdo são fictícios. Todo o processo de preservação das identidades e diretrizes do Comitê de Ética da Unifesp, onde a pesquisa se realizou, foi seguido. Mais detalhes, ver em Bezerra (2019).
} 
Para produção de dados foram realizados, num primeiro momento, entrevistas com os pais a fim de conhecer melhor o contexto familiar, bem como os motivos que os levaram ao se interessar pelo curso de Libras. Também foi feita a observação de aulas vídeo-gravadas do curso de Libras nas quais os pais estavam presentes. As gravações foram dadas aos familiares e, posteriormente, nos reunimos a fim de dialogar sobre estas em sessões reflexivas. De acordo com Pinheiro e Fidalgo $(2019$, p. 6), sessões reflexivas

[...] se caracterizam como espaços de discussão que possibilitam aos interagentes - agentes envolvidos na atividade da linguagem - acolher e analisar as representações, posicionamentos e ações dos outros de forma colaborativa. Na PCCol, esses espaços são guiados por dois objetivos principais: organizar a argumentação [...] e avaliar a teoria que embasa as ações, bem como negociar colaborativamente a construção de novos conhecimentos.

Após essa etapa, foi realizada a transcrição das aulas e das sessões reflexivas. Como categoria de análise, foi utilizada a discussão sobre a qualidade dos tipos de pergunta (ARANHA, 2009), especialmente da pesquisadora que esteve ativa na produção de dados, verificando se as perguntas feitas nas sessões reflexivas proporcionaram caminhos para a construção da reflexão crítica.

Também foi utilizado como categoria de análise o conteúdo temático proposto por Bronckart ([1997] 2012). O quadro 1, que ilustra a estrutura do conteúdo temático, é uma adaptação da discussão sobre as concepções do autor feita por Fidalgo (2006), em que, na busca pelo conteúdo temático, foi construída uma tabela de três colunas.

Na primeira, incluímos um resumo (preferencialmente nominalizado) da pergunta. Essa coluna tem o nome de tema porque a pergunta é o tema para o qual buscamos conseguir elementos, sentidos (respostas). Na segunda, com base nos estudos vygotskianos, trazemos os sentidos ou significados, que, na realidade é o próprio conteúdo temático, ou seja, é a interpretação das pesquisadoras do que se encontra na terceira coluna, onde inserimos o exemplo de fala (analisado) dos participantes. 
Quadro 1- Estrutura de quadro de conteúdo temático ${ }^{10}$

\begin{tabular}{|c|c|c|}
\hline Tema & Sentidos/significados & Exemplos \\
\hline $\begin{array}{c}\text { Pergunta que norteia a } \\
\text { investigação. }\end{array}$ & $\begin{array}{c}\text { Interpretações dos dados pelas } \\
\text { participantes pesquisadoras. }\end{array}$ & $\begin{array}{c}\text { Trechos dados dos } \\
\text { participantes que } \\
\text { exemplificam as } \\
\text { interpretações da }\end{array}$ \\
& & \begin{tabular}{c} 
pesquisadora participante. \\
\hline
\end{tabular} \\
\hline
\end{tabular}

Fonte: Bezerra (2019, p. 110).

Tendo esse arcabouço metodológico como base, demonstraremos a seguir os dados que revelam como eram as concepções dos pais participantes sobre a Libras no início do curso e como o processo de ensino-aprendizagem da língua, bem como a possibilidade de negociação de sentidos por meio da colaboração, (LIBERALI, 2008) proporcionaram a ressignificação.

\section{Discussão dos dados}

Depois de entrevistar Nina e Pedro, fizemos a gravação de 2 aulas do curso de Libras com o intuito de dialogar, em sessões reflexivas, sobre suas impressões em relação à língua, saber como as aulas estavam influenciando a interação com Gustavo e, com isso, construirmos juntos reflexões sobre esse processo de ensino-aprendizagem da Libras.

Nina e Pedro relataram nas entrevistas que não tinham contato com a Libras antes de encontrarem a EMEBS e iniciarem o curso. Diante de uma língua desconhecida e de modalidade tão distinta de sua língua materna, esses pais enfrentam aspectos linguísticos singulares. Ao se debruçarem sobre suas ações como estudantes da Libras, encaram receios e estranhezas relacionadas a uma língua na qual a expressão facial tem uma função primordial.

Com o intuito de possibilitar a reflexão a respeito de como suas ações em sala revelam o julgamento que fazem(iam) dessa língua que estão aprendendo, resgatamos, na sessão reflexiva com Nina, as seguintes partes da aula 4:

Trecho 1 - Aula 4 do curso de Libras ${ }^{11}$

[18mim35s da aula 4]: Prof1: *PINGUIM* / *PINGUIM*

${ }^{10}$ Quadro de Fidalgo (2006) adaptado por Bezerra (2019). 


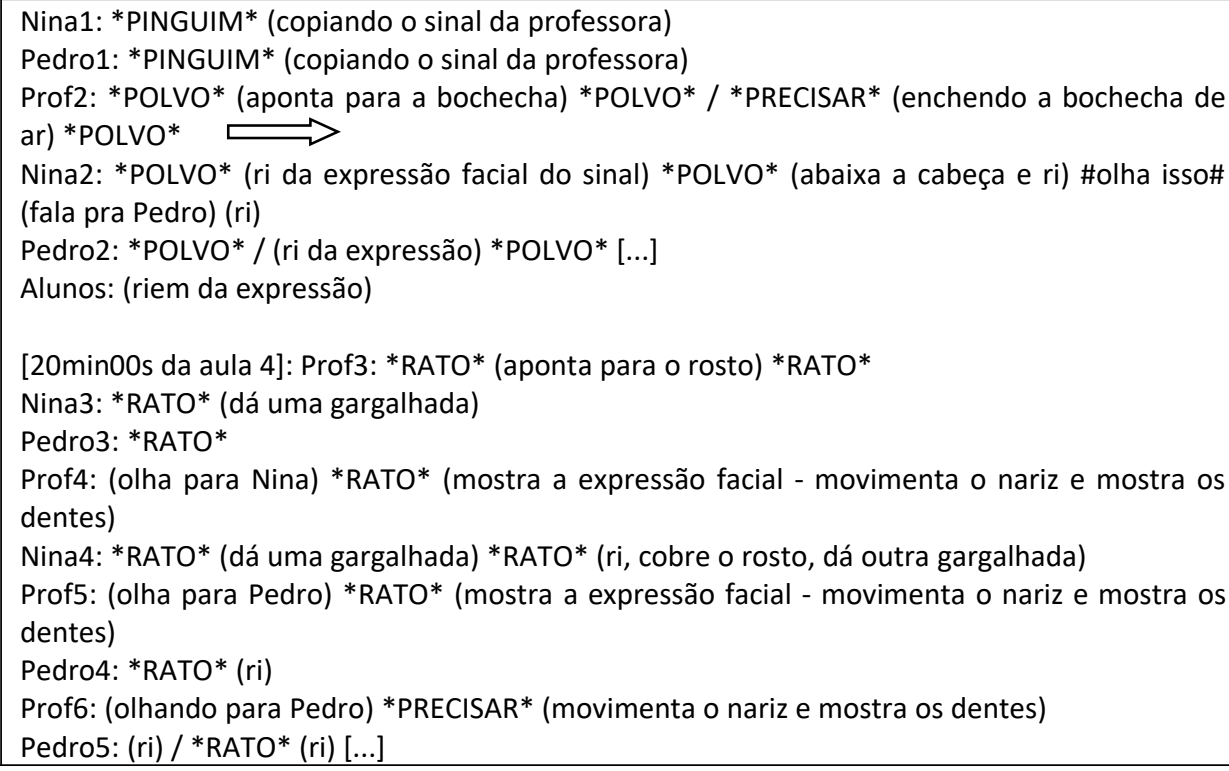

Fonte: Bezerra (2019, p. 142).

Após mostrar os trechos, trazemos a pergunta aberta de clarificação (ARANHA, 2009) "por que que você acha que a professora insiste tanto que vocês façam a expressão bem certinha... nessa hora?" com o objetivo de compreender como Nina interpretava a insistência da professora para que ela fizesse a expressão facial:

\section{Quadro 2 - Sessão reflexiva 2 Nina ${ }^{12}$}

\footnotetext{
${ }^{11}$ Regras de transcrição adaptadas de Felipe (2007) pelos Grupos de Pesquisa GEICS - Estudos sobre Identidade e Cultura Surdas (da UNIFESP) - e ILCAE - Inclusão Linguística em Cenários de Atividades Educacionais (da PUC-SP e da UNIFESP), dos quais as autoras fazem parte (Cf. BEZERRA, 2019).

${ }^{12}$ Regras de transcrição adaptadas de Preti (2001) pelos Grupos de Pesquisa GEICS - Estudos sobre Identidade e Cultura Surdas (da UNIFESP) - e ILCAE - Inclusão Linguística em Cenários de
} 


\begin{tabular}{|c|c|c|}
\hline Tema & Sentido/significado & Fala da participante \\
\hline $\begin{array}{l}\text { Transformação } \\
\text { na } \\
\text { comunicação } \\
\text { pelo uso da } \\
\text { Libras }\end{array}$ & $\begin{array}{l}\text { - Expressão facial é } \\
\text { muito importante } \\
\text { para compreensão } \\
\text { da Libras. } \\
\text { - Expressão facial é } \\
\text { importante para ser } \\
\text { entendido pelo } \\
\text { surdo. }\end{array}$ & $\begin{array}{l}\text { Val6: bom... nessas duas pa:rte... a professora } \\
\text { ((barulho de carros)) ensina o sinal de po::lvo e o } \\
\text { sinal de rato [...] por que que você acha que a } \\
\text { professora insiste tanto que vocês façam a } \\
\text { expressão bem certinha... nessa hora? } \\
\text { Nina6: ((pensativa)) porque assim a Libras não é só } \\
\text { o sinal... é MUlto a expressão facial... e uma coisa } \\
\text { que muitos entendem... você pode não fazer o } \\
\text { sinal direito... mas pela expressão eles ((surdos)) } \\
\text { entendem bem o que é! } \\
\text { Val7: [...] essa AUla...você achava difícil fazer a } \\
\text { expressão facial? } \\
\text { Nina7: mu:::::ito ((risos)) } \\
\text { Val8: por quê? } \\
\text { Nina8: ah... dava uma vergo:::nha ((gargalhou)) dá } \\
\text { uma vergonha. Nossa! foi muito difícil porque:: } \\
\text { essa parte de se comunicar assim... de tentar se } \\
\text { comunicar em Libras e o si... porque ela } \\
\text { ((professora)) não tem vergonha nenhuma né? } \\
\text { ((risos)) então::: foi muito difícil... porque:: as vezes } \\
\text { você expressar o ro:::sto... assim... dá um sorrisinho } \\
\text { é uma coisa... mas você expreSSAR alguns siNAIS } \\
\text { que as pessoas não conhecem... agora você } \\
\text { perguntando ((expressão de pensativa)) porque } \\
\text { algumas pessoas acham estranho... assim como eu } \\
\text { achei estranho no começo. } \\
\text { Val9: e agora? } \\
\text { Nina9: agora não! agora eu entendo TUdo! }\end{array}$ \\
\hline
\end{tabular}

Fonte: Bezerra (2019, p. 142-143).

A partir da questão, a mãe pensa por alguns instantes e diz que na Libras não basta o sinal, mas é fundamental o uso da expressão facial para que a construção do sentido da sinalização seja constituída de forma plena. Em seguida, fazemos outra pergunta aberta de clarificação (ARANHA, 2009) "essa AUla...você achava difícil fazer a expressão facial?" a fim de saber quais as dificuldades de Nina. A mãe confessa ter sentido muita dificuldade. Imediatamente, trazemos a pergunta aberta de explicação (ARANHA, p. 2009) "por quê?" para saber quais obstáculos enfrentava para fazer a expressão facial naquela aula. A mãe revela que, na época, sentia vergonha ao marcar

Atividades Educacionais (da PUC-SP e da UNIFESP), dos quais as autoras fazem parte (Cf. BEZERRA, 2019). 
fortemente a expressão facial e justifica esse sentimento relatando que "agora você perguntando ((expressão de pensativa)) porque algumas pessoas acham estranho... assim como eu achei estranho no começo".

A partir do questionamento, a mãe reflete porque, naquela aula, riu da expressão facial e percebe que, no princípio do processo de ensinoaprendizagem da Libras, esse parâmetro lhe causava estranhezas e que não se sentia confortável em fazê-lo, pensando no que as pessoas e ela julgavam sobre esse aspecto. Na sequência, fazemos a pergunta aberta de clarificação "e agora?" para saber se o sentimento da mãe havia mudado. Em seguida, ela responde que "agora não! agora eu entendo TUdo!".

O sentido que atribuímos a esse dado é de que Nina, no início do curso, compreendia a Libras e, principalmente, o parâmetro expressão facial como algo estranho e até mesmo vergonhoso. Esse ponto revela como a Libras é um idioma ainda pouco conhecido por grande parte da sociedade. Historicamente falando, estudiosos e usuários das línguas de sinais buscam constantemente defender o status de língua e desvinculá-la da visão de mímica, gesto ou linguagem (como linguagem corporal, por exemplo) que é como a sociedade, em geral, vê essa língua (SKLIAR, 1998; PERLIN, 1998; FERNANDES, 2007, 2012; GESSER, 2009). Apesar de muitas mudanças e do reconhecimento da Libras como língua presente não só em estudos e pesquisas, mas também em legislações (BRASIL, 2002, 2005), uma boa parte da população brasileira desconhece o idioma e seu status de língua.

Uma perspectiva nova sobre a Libras surge para Nina somente quando entra no curso. Na sessão reflexiva, que ocorreu depois da última aula do curso, a mãe percebe como julgava a Libras e como, após o processo de ensino-aprendizagem construído no decorrer das aulas, esse julgamento se modifica. Ao final, ela compreende que a Libras e tudo que a constitui não é estranho, é diferente, se estrutura de modo distinto.

Ela demonstrou refletir e comparar o papel da expressão facial na língua portuguesa oral e na Libras e diz "porque assim a Libras não é Só o sinal... é MUlto a expressão facial [...] porque:: às vezes você expressar o ro::sto... assim... dá um sorrisinho é uma coisa... mas você expreSSAR alguns siNAIS..." Para esse dado, atribuímos o sentido de que Nina mostrou reflexão sobre como, diferentemente do português, a expressão facial na Libras é indissociável do sinal feito com a mão; a expressão facial compõe o sinal, que 
só está completo se os parâmetros ${ }^{13}$ forem respeitados. Esse parâmetro (a expressão facial) tem papel fundamental na construção de sentido da Libras. Assim, para que "eles ((surdos))" compreendam sua sinalização e a comunicação seja efetivada, é essencial o uso correto da expressão facial.

A construção da consciência do que ela pensava antes sobre a Libras e como isso se transformou por causa do curso foi possível graças à sessão reflexiva na qual Nina e a pesquisadora participante construíram um processo de negociação e reflexão de sentidos revelados em suas ações e, a partir disso, os transformaram (MAGALHÃES, [1994] 2007a, [1998] 2007b; LIBERALI, 2008).

A mesma aula foi discutida na sessão reflexiva com Pedro:

Quadro 3 - Sessão reflexiva 2 Pedro

\begin{tabular}{|c|c|c|}
\hline Tema & $\begin{array}{c}\text { Sentido/ } \\
\text { significado }\end{array}$ & Fala do participante \\
\hline $\begin{array}{l}\text { Transformação } \\
\text { na } \\
\text { comunicação } \\
\text { pelo uso da } \\
\text { Libras }\end{array}$ & $\begin{array}{l}\text { - Expressão facial é } \\
\text { muito importante } \\
\text { para compreensão } \\
\text { da Libras. } \\
\text { - Expressão facial é } \\
\text { importante para } \\
\text { ser entendido pelo } \\
\text { seu interlocutor. }\end{array}$ & $\begin{array}{l}\text { Val9: [...] Por que você acha que a professora insistiu } \\
\text { que vocês fizessem a expressão facial bem } \\
\text { direitinho? } \\
\text { Pedro9: então:: agora ((pensativo)) pelo que eu } \\
\text { Acho:: e porque::: pra saber expressar MAIS né? o } \\
\text { sinal... pra expressar bastante o sina:::I e também } \\
\text { pra pessoa que VÊ... vir a perceber que é um RAto } \\
\text { né? porque só fazendo o sinal a pessoa não vai ver } \\
\text { então tem que fazer o:: a forma dos de::ntes da boca } \\
\text { certinho pra pegar o sinal rato. } \\
\text { Val10: é:: na parte da expressão vocês riram... por } \\
\text { que vocês acharam engraçado? } \\
\text { Pedro10: eu achei engraçado ah... a expressão facial } \\
\text { fica muito engraçada não tinha como não rir ((risos)). } \\
\text { Val11: mas e agora [...]? } \\
\text { Pedro11: ah... sim... já acostumamos... no começo a } \\
\text { gente até brincava... dava risada juntos... mas agora } \\
\text { não... a gente pegou a expressão certi::nho. } \\
\text { Val12: e nessa parte que a professora insiste em } \\
\text { fazer certinho é porque PREcisa fazer a expressão? } \\
\text { Pedro12: isso! que precisa fazer a expressão! porque } \\
\text { se for fazer somente... como posso dizer o ges... o } \\
\text { sinal não ia adiantar né? pra entender [...] não ia }\end{array}$ \\
\hline
\end{tabular}

${ }^{13}$ Embora não seja alvo deste artigo, para compor o significado dos sinais, são utilizados 5 parâmetros na Libras: configuração de mão, ponto de articulação, movimento, direcionalidade ou orientação e expressão facial e/ou corporal. Para mais informações a esse respeito, ver Quadros; Karnopp (2004) e Lacerda; Santos (2018). 


\begin{tabular}{|l|l|l|}
\hline & $\begin{array}{l}\text { adiantar... aí tem que fazer a expressão facial pra } \\
\text { facilitar na identificação né? }\end{array}$ \\
\hline
\end{tabular}

Fonte: Bezerra (2019, p. 145).

Fazemos uma pergunta aberta de clarificação (ARANHA, 2009) com a finalidade de saber como Pedro compreende o destaque que a professora dava às expressões faciais. O rapaz reflete e diz que "só fazendo o sinal a pessoa não vai ver. Então tem que fazer o:: a forma dos de::ntes da boca certinho pra pegar o sinal rato". Posteriormente, fazemos uma pergunta aberta de explicação (ARANHA, 2009) de forma a entender os motivos que o levaram a rir das expressões faciais. O participante revela que achava o parâmetro engraçado. Ao questionar como ele enxergava as expressões faciais ao final do curso, este informa que se acostumou com o uso do parâmetro e percebeu que, sem esse aspecto, a compreensão do sinal não acontece.

O mais revelador nesses dados vem do fato de que as sessões reflexivas de Nina e Pedro aconteceram no mesmo dia, uma em seguida à outra. Assim sendo, não tiveram a chance de dialogar sobre as perguntas. Mesmo assim, a construção de suas reflexões sobre esse ponto da aula 4 é muito próxima. Com isso, ambos os participantes revelaram caminhos parecidos no processo de (2) Informar - o que significa meu riso ao usar a expressão facial?; (3) Confrontar - por que agi desse modo? O que essa ação revela? e (4) Reconstruir - como mudar minha visão sobre a Libras e a expressão facial? - passos que, segundo Smyth (1992), são essenciais para que os participantes transformem as suas práticas, suas crenças (em suma, seus sentidos) por meio da reflexão sobre a ação (LIBERALI, 2008; MAGALHÃES, [1994] 2007a, [1998] 2007b).

Esse processo de reflexão influencia também a construção comunicativa que os pais têm com o filho no contexto doméstico. A primeira sessão reflexiva que foi feita com Nina ocorreu para que dialogássemos sobre alguns pontos de sua entrevista. Em certo ponto da sessão, conversamos acerca do que a mãe relatou na entrevista, sobre como era, para ela, aprender a Libras:

Trecho 2 - Entrevista Nina

[26min38s da entrevista] Nina32: então... no começo... na primeira aula meu Deus eu fiquei 
desesperada! Eu falei nossa Pedro eu não vou aprender eu não vou aprende:r ((sorriu)) ele disse CAL:::ma!

Fonte: Bezerra (2019, p. 146).

A intenção de rever esse aspecto na sessão era compreender melhor quais eram as dificuldades que Nina sentia no processo de ensinoaprendizagem da língua de sinais, algo que não havia ficado muito claro, visto que Nina trouxe um ponto de vista ("Eu não vou aprender") para o qual não Ihe foi solicitada uma explicação ("Por que você achava que não aprenderia?"). $\mathrm{Na}$ tentativa de descobrir o que ela entendia por sua dificuldade de aprender, trouxemos uma pergunta aberta de clarificação (ARANHA, 2009) "qual a parte mais: difícil na Libras que você acha?" Esta pergunta, a mãe responde no decorrer da sessão reflexiva:

Quadro 4 - Sessão reflexiva 1 Nina

\begin{tabular}{|c|c|c|}
\hline Tema & Sentido/significado & Fala da participante \\
\hline $\begin{array}{l}\text { Transformação na } \\
\text { comunicação por } \\
\text { meio da Libras }\end{array}$ & $\begin{array}{l}\text { - Expressão facial auxilia } \\
\text { no processo de interação } \\
\text { em Libras. }\end{array}$ & $\begin{array}{l}\text { Val49: e qual a parte mais:: difícil na Libras } \\
\text { que você acha? } \\
\text { Nina41: a parte de comunicação de } \\
\text { encaixar frase... sabe? [...]... porque... na } \\
\text { frente do Gustavo É Libras... não sabe de } \\
\text { nada? IMPROVIsa... tudo no improviso mas } \\
\text { em Libras... lá em casa agora é assim... a } \\
\text { gente sabe po::uco mas é aquela coisa } \\
\text { [...]mas:.: agora em casa a gente sempre } \\
\text { tenta se comunicar em Libras... foca na } \\
\text { Libras... principalmente com ele [...] a gente } \\
\text { interpre::ta é:: muita coisa que a professora } \\
\text { fez hoje... a gente é muito isso! [...] então é } \\
\text { aquela coisa você não sabe o sinal? A gente } \\
\text { vai imitando os bi::chos... muita } \\
\text { expressão... faz qualquer coisa! ! minha } \\
\text { CASA você não tem noção! }\end{array}$ \\
\hline
\end{tabular}

Fonte: Bezerra (2019, p. 147).

Nina contou que tem muita dificuldade na construção de frases em Libras, mas usa outras estratégias para se comunicar com Gustavo, sempre utilizando tudo o que sabe em língua de sinais. Se não consegue formular frases, utiliza outros aspectos da língua para efetivar a comunicação com o filho. É o que ela indica quando diz: “... lá em casa agora é assim... a gente sabe 
po::uco mas é aquela coisa [...] mas::: agora em casa a gente sempre tenta se comunicar em Libras... foca na Libras... principalmente com ele [...] a gente interpre::ta é:: muita coisa que a professora fez hoje... a gente é muito isso! [...] então é aquela coisa você não sabe o sinal? A gente vai imitando os bi::chos... muita expressão..." O que a mãe está dizendo é que usa o que, em ensino de línguas estrangeiras e segunda língua, chamamos de paráfrase, ou seja, uma explicação para o termo que desconhecemos na língua. E, ao descrever o uso da Libras em casa, a mãe tenta explicar o que os estudiosos dessa língua definem como classificadores.

O dado discutido aqui foi produzido ao final da aula 20 do curso. Nesse dia, a instrutora trabalhou os classificadores ${ }^{14}$ e o modo como a expressão facial é constituinte fundamental desse aspecto da língua. Vale destacar que não somente nessa aula, mas em várias outras, a instrutora acentua a importância do parâmetro expressão facial. Ao aprender no curso a relevância de explorar o uso dos classificadores e expressão facial, Nina percebeu que esses pontos são imprescindíveis para a interação com o filho. Então, mesmo não dominando a língua, Nina utiliza o que sabe, explorando ao máximo as competências que alcançou no curso de Libras. Evidenciou que o mais importante é utilizar sempre a língua de sinais ao interagir com o filho. Esse dado corrobora com o que pesquisadores da educação de surdos defendem no que diz respeito à importância de as famílias ouvintes aprenderem a Libras e, com isso, construírem um processo de comunicação mais fluido no contexto

\footnotetext{
${ }^{14}$ Ferreira (2010, p. 79), ao explicar a estrutura interna dos sinais com base nos teóricos Klima e Bellugi (1979), expõe que, assim "como as línguas orais, as línguas de sinais exibem a dupla articulação", ou seja, "possuem unidades significativas" (morfemas) "constituídas a partir de unidades arbitrárias e sem significado" (fonemas). A diferença é que, nas línguas orais, os fonemas são produzidos pela passagem de ar pela laringe, nariz e boca, e, nas línguas de sinais, a estrutura fonológica se organiza a partir de parâmetros visuais. Além dessa distinção, a autora ressalta outra: a organização fonológica das línguas. Enquanto nas línguas orais há linearidade na produção dos fonemas no momento da fala, nas línguas de sinais existe a simultaneidade. Gesser (2009) diz que os sinais são compostos pelos seguintes parâmetros: configuração de mão (diz respeito à forma que a mão toma na realização do sinal), ponto de articulação (local do corpo ou espaço no qual o sinal é articulado), movimento (conjunto de movimentos que constituem o sinal), orientação da palma da mão (direção da palma da mão durante a produção do sinal) e expressões não manuais (expressões faciais e corporais que "compõem a estrutura da língua; por exemplo, na marcação de formas sintáticas (de negação, afirmação) e atuação como componente lexical (de intensidade)" (GESSER, 2009, p. 18). Já os classificadores podem ser entendidos como similares à paráfrase, i.e., na falta de um sinal, explica-se (Cf. GESSER, 2009; FERREIRA, 2010)
} 
doméstico (LACERDA E LODI, 2009; GÓES, 2012; LACERDA, 2013; MONTEIRO, 2013).

Além da aula 4, resgatamos também aspectos da aula 9. Nela, Gustavo estava presente por não ser dia letivo para ele. Nina e Pedro o levaram para o curso. Destacamos que, antes de fazer perguntas sobre as aulas, a pesquisadora presente perguntou aos pais participantes se gostariam de conversar sobre algum ponto que acharam relevantes. Sobre a aula 9 a mãe revela algumas reflexões:

Quadro 5 - Sessão reflexiva 2 Nina

\begin{tabular}{|c|c|c|}
\hline Tema & Sentido/significado & Fala da participante \\
\hline $\begin{array}{l}\text { Transformação } \\
\text { na comunicação } \\
\text { por meio da } \\
\text { Libras }\end{array}$ & $\begin{array}{l}\text { - Surdo tem mais facilidade } \\
\text { com a Libras. } \\
\text {-Libras é a língua do surdo. }\end{array}$ & $\begin{array}{l}\text { Nina10: então... nessa AUla foi bom } \\
\text { porque ela ((professora)) ia fazendo os } \\
\text { sinais e o Gustavo fazia junto... não sei } \\
\text { se você lembra... você prestou atenção? } \\
\text { Val11: prestei. } \\
\text { Nina11: ela fazia o sinal e ele fazia } \\
\text { também! ((risos)) ele se divertiu muito } \\
\text { nesse dia ((risos)) [...] } \\
\text { Nina12: então... pra ele é mais fácil... } \\
\text { BEM mais fácil... ou até:: hoje... até em } \\
\text { casa é bem mais fácil... às vezes eu faço } \\
\text { o sinal errado e ele faz certo! o sinal } \\
\text { de::le mesmo... às vezes eu faço aqui:: } \\
\text { ele faz... mostra que é aqui do lado } \\
\text { sabe? e ele é muito inteligente! } \\
\text { Val13: e por que você acha que pra ele é } \\
\text { mais fácil aprender os sinais? } \\
\text { Nina13: eu acho porque ele é surdo... } \\
\text { então isso é uma facilidade maior... } \\
\text { porque a única forma dele se comunicar } \\
\text { é pelo sinal! então essa é a facilidade } \\
\text { nas coisas. }\end{array}$ \\
\hline
\end{tabular}

Fonte: Bezerra (2019, p. 148).

Nina relata, nessa sessão, alguns pontos das ações de Gustavo em sala, que ela observou com mais atenção ao ver a gravação. Percebeu que o filho faz os sinais junto com a professora e que ele tem mais facilidade para sinalizar. Em seguida, fazemos uma pergunta aberta de clarificação (ARANHA, 2009) para entender por que a mãe achava que Gustavo aprendia a Libras mais facilmente. Nina respondeu que isso ocorria porque o filho era surdo e, 
consequentemente, tinha mais facilidade em sinalizar. De acordo com a mãe, isso acontece porque a Libras é a única forma de o filho se comunicar. O sentido que demos a esse dado é de que a mãe compreendeu que língua de sinais é o idioma pelo qual o filho consegue interagir mais facilmente.

Autores como Finau (2006), Lacerda e Lodi (2009), Góes (2012), Fernandes (2012) e Franco (2015) afirmam que o processo de ensinoaprendizagem da Libras é mais fácil para a criança surda, pois o idioma se desenvolve em uma modalidade (espaço-visual) acessível, diferente da língua oral, que é acessada e apreendida pelo surdo por processos diferentes. Além disso, é comum ouvirmos relatos de pais e professores sobre o quão ávidas as crianças surdas ficam quando descobrem que podem se comunicar. Via de regra, os relatos indicam que elas aprendem a língua muito rapidamente.

No caso de Gustavo com os pais, ele logo se torna o que Vygotsky ([1934] 1991) chama de par mais experiente, ou seja, aquele que está um pouco à frente dos outros (os pais) e pode, portanto, ajudá-los a compreender o ponto de articulação dos sinais, por exemplo, quando a mãe diz: "até em casa é bem mais fácil... às vezes eu faço o sinal errado e ele faz certo! o sinal de::le mesmo... às vezes eu faço aqui:: ele faz... mostra que é aqui do lado sabe?" Vale lembrar que, como afirma Fidalgo (2018, p.28), nem sempre é o adulto (pai, mãe, professor) o par mais experiente. O professor pode ter mais experiência quanto ao conteúdo que ensina, quanto à organização da sala e quanto a metodologias, mas o aluno tem mais experiência sobre si e sobre sua aprendizagem e, no caso do aluno surdo, sobre a sua língua (a menos que o adulto também seja surdo).

Em suma, o processo de ensino-aprendizagem da Libras promoveu grandes mudanças, proporcionando a comunicação entre os membros dessa família e mudando a concepção que os adultos tinham sobre a criança e sua possibilidade de aprender e de se comunicar como qualquer outra. Ao mesmo tempo, por meio das sessões reflexivas, os pais de Gustavo refletiram sobre suas ações em sala de aula e sobre as transformações que vivenciaram no processo de ensino-aprendizagem da Libras, percebendo como este pôde abrir portas para uma interação melhor com o filho surdo.

\section{Considerações finais}


Primeiramente, como já discutido, percebe-se como o curso de Libras possibilitou uma mudança de concepção não só sobre a língua em si, mas sobre o processo comunicativo no contexto doméstico. Nina e Pedro tiveram, no curso de Libras, a oportunidade de conhecer a língua de sinais como idioma de Gustavo, de aprender estratégias comunicativas específicas de uma língua visual-gestual e descobrir como os parâmetros, como o da expressão facial, assim como os classificadores são essenciais para a construção das interações em Libras com o filho.

Por consequência, esse processo de reflexão proporcionou ressignificação das concepções que os pais tinham sobre a Libras, promovendo a conscientização de como o ensino-aprendizagem dessa língua transformou positivamente o processo de interação com Gustavo.

É importante lembrar que esse processo de ressignificação só foi possível por meio das sessões reflexivas, em um trabalho colaborativo de reconstrução dos significados, visto que é muito comum as pessoas não terem consciência de sua aprendizagem e do impacto transformador que esta tem sobre as suas vidas. Ao exporem suas percepções, incógnitas e contradições, os participantes revisitavam seus momentos de aprendizagem, mas já com o distanciamento que lhes permitia olharem as cenas como se estivessem fora delas, como quem as assiste e analisa. Esse processo ocorreu sempre guiado pelas perguntas da pesquisadora presente e apoiado por sua leitura dos discursos desses participantes, inclusive a leitura do que não foi claramente verbalizado. Nesse espaço de diálogo criam-se e se revisitam zonas de desenvolvimento proximal (ZDP) que, segundo Vygotsky ([1934] 1991), são espaços de promoção de aprendizagem com o apoio dos demais (os pares mais experientes); espaços em que todos os envolvidos podem rever suas convicções, ressignificando-as.

É importante também lembrar que esse caminho de ressignificação via ZDP não é linear. Os aprendizes seguem trilhas diferentes para chegarem a novos sentidos pessoais, mesmo tendo participado da construção coletiva de significados de forma conjunta e colaborativa. Para Vygotsky ([1934] 1991, p. 117-118), "um aspecto essencial da aprendizagem é o fato de criar a zona de desenvolvimento proximal, ou seja, a aprendizagem desperta vários processos internos de desenvolvimento" (desse modo, não há linearidade no conceito de ZPD). Esses processos só entram em ação quando a pessoa está em colaboração com outros e "uma vez internalizados, esses processos tornam-se 
parte [...] do desenvolvimento independente" (idem) da pessoa que os vivencia.

Então, a importância de momentos colaborativos como os que os pais do Gustavo viveram é que o ensino-aprendizado que experienciaram "resulta em desenvolvimento mental" (para eles e, posteriormente, em ensinoaprendizagem-que-resulta-em-desenvolvimento para o filho e para eles próprios em um ciclo constante). É ensino-aprendizagem que

[...] põe em movimento diversos processos de desenvolvimento que, de outra forma seriam impossíveis de acontecer. Assim, a aprendizagem é um aspecto necessário e universal do processo de desenvolvimento das funções psicológicas culturalmente organizadas e especificamente humanas (VYGOTSKY, [1934] 1991, p. 118).

Desta forma, como fica evidente neste estudo, apoiado na teoria sóciohistórico-cultural, o alicerce principal do desenvolvimento humano não é, não está e não surge do biológico, mas da realidade social, histórica e cultural, das interações que o ser humano mantém com seus pares, da história que, dialeticamente, ele constrói e o transforma, da cultura que ele cria, produz e internaliza, sendo outro ao final de cada interação sócio-histórica e cultural. Assim, o desenvolvimento da espécie humana é processo e produto das relações sociais construídas colaborativamente e nas quais o ensinoaprendizagem é o elemento que o antecipa e o estimula (VYGOTSKY, [1934] 1991).

\section{Referências}

AGUIAR, Wanda Maria Junqueira, SOARES, Júlio Ribeiro, MACHADO, Virgínia Campos. Núcleos de significação: uma proposta histórico-dialética de apresentação das significações. Cadernos de Pesquisa, São Paulo, v.45, n.155, jan./mar. 2015. Disponível em: https://www.scielo.br/scielo.php?pid=S010015742015000100056\&script=sci_abstract\&tlng=pt. Acesso em: 07 mar. 2019.

ARANHA, Elvira Maria Godinho. 0 papel do diretor escolar: uma discussão colaborativa. 2009. 189f. Dissertação (Mestrado) - Departamento de Linguística Aplicada e Estudos da Linguagem, Pontifícia Universidade Católica de São Paulo, São Paulo, 2009. 
BEZERRA, Valéria da Silva. A Libras e sua capacidade de romper silêncios e criar laços no contexto familiar pais ouvintes de criança surda. 2019. $235 \mathrm{f}$. Dissertação (Mestrado em Educação e Saúde na Infância e na Adolescência), Universidade Federal de São Paulo, Guarulhos, 2019.

BRASIL. Lei no 10.436, de 24 de abril de 2002. Dispõe sobre a Língua Brasileira de Sinais - Libras e dá outras providências. Diário Oficial da União, Brasília, DF, 14 abr. 2002. Disponível em:

http://www.planalto.gov.br/ccivil_03/leis/2002/L10436.htm. Acesso em: 22 maio 2020.

BRASIL. Decreto no 5.626, de 22 de dezembro de 2005. Regulamenta a Lei $n$ ㅇ 10.436, de 24 de abril de 2002, que dispõe sobre a Língua Brasileira de Sinais Libras, e o art. 18 da Lei no 10.098, de 19 dez. 2000. Diário Oficial da União, Brasília, DF, 23 dez. 2005. Disponível em:

http://www.planalto.gov.br/ccivil_03/_ato2004-2006/2005/decreto/d5626.ht m. Acesso em: 22 maio 2020.

BRONCKART, Jean-Paul. Atividade de linguagem, textos e discursos: por um interacionismo sociodiscursivo. Tradução: Anna Rachel Machado, Péricles Cunha. 2. ed. São Paulo: EDUC, [1997] 2012.

FELIPE, Tanya Amara. Libras em contexto: curso básico. Rio de Janeiro: FENEIS: livro do estudante, 2007.

FERNANDES, Sueli. Surdez e Linguagens. In: FERNANDES, Sueli. Educação de Surdos. Curitiba: Editora Ibpex, 2007, p. 85-116.

FERNANDES, Sueli. O que os Surdos Adultos Têm a Dizer aos Pais de Crianças Surdas? Secretaria Estadual de Educação do Paraná, Curitiba, v. 1, n. 1, 2012. Disponível em:

http://www.educadores.diaadia.pr.gov.br/arquivos/File/artigos_edespecial/ sueli.pdf. Acesso em: 30 maio 2020.

FIDALGO. Sueli Salles. A linguagem da inclusão/exclusão social-escolar na história, nas leis e na prática educacional. 2006. 341f. Tese (Doutorado)- 
Departamento de Linguística Aplicada e Estudos da Linguagem, Pontifícia Universidade Católica de São Paulo, São Paulo, 2006.

FIDALGO. Sueli Salles. A linguagem da exclusão e inclusão social na escola. São Paulo: Editora UNIFESP, 2018.

FIDALGO. Sueli Salles, MAGALHAES, Maria Cecilia Camargo. The method in Vygotsky: social compensation to achieve higher psychological functions and social changes. In: TANZI NETO, Adolfo; DAFERMOS, Manolis. e LIBERALI, Fernanda Coelho. (orgs) Revisiting Vygotsky for social change: bringing together theory and practice. New York: Peter Lang. 2021".

FINAU, Rossana. Possíveis encontros entre cultura surda, ensino e linguística. In: QUADROS, Ronice Muller de, STUMPF. Marianne Rossi, (orgs). Estudos Surdos I. Petrópolis: Arara Azul, 2006.

FRANCO, Lidiane Helena Reinaldo. Língua Brasileira de Sinais: uma ponte de amor entre pais ouvintes e filhos surdos. 2015. 141f. Dissertação (Mestrado) Departamento de Serviço Social, Pontifícia Universidade Católica de São Paulo, São Paulo, 2015.

GESSER, Audrei. Libras? que língua é essa?: crenças e preconceitos em torno da língua de sinais e da realidade surda. São Paulo: Parábola, 2009.

GÓES, Maria Cecília Rafael de. Linguagem, surdez e educação. 4. ed. Campinas: Autores Associados, 2012.

KELMAN Celeste Azulay. et al. Surdez e família: facetas das relações parentais no cotidiano comunicativo bilíngue. Revista Linhas Críticas, Brasília, v. 17, n. 33, maio/ago. 2011. Disponível em:

http://periodicos.unb.br/index.php/linhascriticas/article/view/3737. Acesso em: 30 maio 2020.

KEMMIS, Stephen. Critical Reflection. In: WIDEEN, M.F.; ANDREWS, I. Staff development for school improvement: a focus on the teacher. New York: Falmer Press. 1987. p. 73-90. 
LACERDA, Cristina Broglia Feitosa de. Proposta de educação bilíngue para surdos (Apresentação Oral). Seminário Internacional de Bilinguismo e Formação de Intérprete e Guia-intérprete Educacional, São Paulo: 17 a 18 de set. 2013.

LACERDA, Cristina Broglia Feitosa de; LODI, Ana Cláudia Balieiro. A inclusão escolar bilíngue de alunos surdos: princípios, breve histórico e perspectiva. In: LACERDA, Cristina Broglia Feitosa de; LODI, Ana Cláudia Balieiro. Uma escola duas línguas: letramentos em língua portuguesa e língua de sinais nas etapas iniciais de escolarização. Porto Alegre: Editora Mediação, 2009, pp. 11-32.

LACERDA, Cristina Broglia Feitosa de. SANTOS, Lara Ferreira dos (orgs). Tenho um aluno surdo, e agora? São Carlos: Edufscar. 2018.

LIBERALI, Fernanda Coelho. Formação crítica de educadores: questões fundamentais. Taubaté: Cabral Editora Universitária, 2008.

LIBERALI, Fernanda Coelho. Transforming Urban Education in São Paulo: Insights into a Critical-Collaborative School Project. Revista DELTA, São Paulo, v. 35, n. 3, 2019. Disponível em: https://doi.org/10.1590/1678460×2019350302. Acesso em: 19 maio 2020.

MAGALHÃES, Maria Cecilia Camargo. A Etnografia Colaborativa: pesquisa e formação profissional. In: FIDALGO, Sueli Salles., SHIMOURA, Alzira Silva. (orgs). Pesquisa Crítica de Colaboração: um percurso na formação docente. São Paulo: Ductor, [1994] 2007a, p. 60-68.

MAGALHÃES, Maria Cecilia Camargo. Formação Contínua de Professores: sessão reflexiva como espaço de negociação entre professores e pesquisador externo. In: FIDALGO, Sueli Salles., SHIMOURA, Alzira Silva. (orgs). Pesquisa Crítica de Colaboração: um percurso na formação docente. São Paulo: Ductor, [1998] 2007b, p. 104-121.

MAGALHÃES, Maria Cecilia Camargo. Pesquisa crítica de colaboração: escolhas epistemo-metodológicas na organização e condução de pesquisas de 
intervenção no contexto escolar In: MAGALHÃES, Maria Cecilia Camargo, FIDALGO, Sueli Salles. (orgs). Questões de método e de Linguagem na Formação Docente. Campinas: Mercado das Letras, 2011, p.13-40.

MAGALHÃES, Maria Cecilia Camargo. A linguagem na formação de professores reflexivos e críticos In MAGALHÃES, Maria Cecília Carmargo. A formação do professor como um profissional critico. Campinas, SP: Mercado de Letras, 2004, p. 59-86.

MAGALHÃES, Maria Cecilia Camargo; FIDALGO, Sueli Salles. Reviewing Critical Research Methodologies for Teacher Education in Applied Linguistics. Revista DELTA, São Paulo, v. 35, n. 3, 2019.

MONTEIRO, Myrna Salermo. Aquisição da Língua de Sinais como 1a língua para surdos (Apresentação oral). Seminário Internacional de Bilinguismo e Formação de Intérprete e Guia-intérprete Educacional. São Paulo: 17 a 18 set. 2013.

NININ, Maria Otília Guimarães, MAGALHÃES, Maria Cecília Camargo. A linguagem da colaboração crítica no desenvolvimento da agência de professores de ensino médio em serviço. Alfa: Revista de Linguística. São Paulo, v. 61, n. 3, 2017. Disponível em: http://doi.org/10.1590/1981-57941711-7. Acesso em: 14 maio 2020.

PERLIN, Gládis. Identidades Surdas. In: SKLIAR, Carlos. (org.) A Surdez, um olhar sobre as diferenças. Porto Alegre: Mediação, 1998.

PINHEIRO, Lucineide Machado; FIDALGO, Sueli Salles. Adaptações Curriculares na "Inclusão" Escolar de alunos surdos: intervenções colaborativas. Revista Brasileira de Pesquisa Sócio-histórico-cultural e da Atividade. Rio de Janeiro, v. 1, n. 1, 2019.

PRETI, Dino. Análise de textos orais. São Paulo. São Paulo: Humanitas Publicações FFLCH/USP, 2001.

QUADROS, Ronice Müller de \& KARNOPP, Lodenir Becker. Língua de sinais brasileira: estudos linguísticos. Porto Alegre: Editora ArtMed, 2004. 
SANTANA, Ana Paula, GUARINELLO Ana Cristina, BERGAMO, Alexandre. A clínica fonoaudiológica e a aquisição do português como segunda língua para surdos. Revista Distúrbios da Comunicação. São Paulo, v. 25, n. 3, dez. 2013. Disponível em: https://revistas.pucsp.br/dic/article/view/17734/13218. Acesso em: 28 mai. 2020.

SKLIAR, Carlos. Apresentação. In: SKLIAR, Carlos. A surdez: um olhar sobre as diferenças. Porto Alegre: Mediação, 1998.

SMYTH, John. Teachers' Work and the Politics of Reflection. American Education Research Journal. Washington, v. 29, n. 2, 1992, pp. 267-300.

SMOLKA, Ana Luiza Bustamante; LAPLANE, Adriana Lia Friszman de. Processos de cultura e internalização. Revista Viver Mente e Cérebro. Coleção Memória da Pedagogia: Rio de Janeiro, n.1, p. 76-83, 2005.

SOUZA, Jaqueline Gomes. Sessões Reflexivas sobre a atividade de contar de histórias para surdos: contribuições para a ressignificação de práticas docentes. 2017. 216f. Dissertação (Mestrado) - Programa de Educação e Saúde na Infância e na Adolescência, Universidade Federal de São Paulo, Guarulhos, 2017.

VYGOTSKY, Lev Semyonovich. La coletividad como factor de desarrollo del nino deficiente. In: VYGOTSKY, Lev Semyonovich. Obras Escogidas V: fundamentos de defectología. Moscou/Madrid: Editorial Pedagógica Visor, [1931] 1997a.

VYGOTSKY, Lev Semyonovich. Principios de la educación social de los niños sordomudos. In: VYGOTSKY, Lev Semyonovich. Obras Escogidas V:

fundamentos de defectología. Moscou/Madrid: Editorial Pedagógica Visor, [1930] 1997b.

VYGOTSKY, Lev Semyonovich. Verificación experimental de los nuevos métodos de los niños sordomudos. In: VYGOTSKY, Lev Semyonovich. Obras Escogidas V: fundamentos de defectología. Moscou/Madrid: Editorial Pedagógica Visor, [s/d] 1997c. 
VYGOTSKY, Lev Semyonovich. Formação social da mente. 4. ed. brasileira. Sao Paulo: Martins Fontes, [1930] 1991. Disponível em: http://www.pr.gov.br/bpp. Acesso em: 14 maio 2020.

VYGOTSKY, Lev Semyonovich. Construção do Pensamento e da Linguagem.

Edição: Ridendo Castigat Mores, Versão para o eBook: eBookBrasil.com, [1934] 2001.

YUE, Andrea Henlin. Intervenção bilíngue: percepção dos pais quanto a mudança na comunicação com seus filhos surdos. 2010. 141f. Dissertação (Mestrado em Medicina)- Faculdade de Medicina, Universidade de São Paulo, São Paulo, 2010. 